\title{
Make my day! Teachers' experienced emotions in their pedagogical work with disengaged students
}

\author{
Marieke Fix, Henk Ritzen, Wilmad Kuiper, Jules Pieters
}

\begin{abstract}
The present study researched teachers' emotions related to their pedagogical work with disengaged students. The aim of the study was to investigate teachers' emotions experienced during classroom practice and how emotions were related to their perceived well-being. Based on the literature, we assumed that teachers' perceived well-being was affected by the emotions in their classroom practice through their feelings of autonomy, competence and relatedness. Data were collected using qualitative methods. In our results, we reported that teachers experienced mixed emotions elicited by interactions with students, student learning, colleagues and the programme. We determined the characteristics of classroom practices that contribute positively to teachers' perceived well-being as well as characteristics that diminish teachers' perceived well-being. Implications for practice are discussed.
\end{abstract}

Keywords: teacher's emotions, teachers' perceived well-being, students at risk, self-determination theory

\section{Introduction}

Happy and satisfied teachers are better teachers. They perform better in their pedagogical practices or classrooms compared to their unhappy colleagues and moreover enhance students' motivation and achievement (Frenzel, Goetz, Lüdtke, Pekrun \& Sutton, 2009; Jalali \& Heidari, 2016). According to the literature, teachers' emotions are dependent on the pedagogical relationships between teachers and students (Frenzel, 2014; Frenzel et al., 
2009; Hagenauer, Hascher \& Volet, 2015; Spilt, Koomen \& Thijs, 2011; Veldman, van Tartwijk, Brekelmans \& Wubbels, 2013). Teaching, leading and learning can be considered "irretrievably emotional in character" (Hargreaves, 2000, p. 812), but the emotions involved seem to be ambiguous and may include feelings enjoyment and pride as well as anxiety and anger (Bullough \& Pinnegar, 2009; Frenzel, 2014). Chang (2009) argues that "the more teachers care about students the more likely they get angry or frustrated by students" (p. 20). In addition, Frenzel et al. (2009), Frenzel (2014) and Shen et al. (2015) point out that classroom emotions are mutual in character as teachers and students affect and influence each other's feelings positively as well as negatively.

The regulation of emotions can be considered part of teachers' pedagogical practice. Teachers must in the first place act upon students' emotional development to achieve optimal learning (Pekrun, 2017). Some students might have negative experiences at school that elicit negative emotions such as frustration or disappointment that thwart optimal learning. In the meantime teachers have to regulate their own feelings and emotions. Chang (2013) postulates that little is known of the emotional process that teachers experience in their classrooms, which raises the question how teachers' emotions in practice can be understood. Given that teachers' emotions depend on the individualistic and contextual appraisal and experiences of teachers (Chang, 2013; Frenzel, 2014; Lazarus, 2006; Maag, 2008), we assume there is no single comprehensive answer to that question. Yet investigating teachers' emotions in their practice can provide valuable information for understanding how emotions influence classroom practice, both in terms of the students' learning as well as the teachers' well-being (Frenzel et al., 2009; Jalali \& Heidari, 2016).

In our study we aimed to identify practices that have an emotional impact on teachers, and we wanted to determine the cause of these emotions and how these were related to the concepts of teachers' well-being.

\section{Theoretical Framework}

\section{Teachers' emotions}

Teachers' subjective well-being and sustainability of performance are related to the emotional load during teaching (Bullough \& Pinnegar, 2009; Chang, 2009, 2013; De Stercke, Goyette \& Robertson, 2015; Maslach, Schaufeli \& Leiter, 2001). Frenzel (2014) provides an insight into the emo- 
tions that teachers experience in their profession by focusing upon their teaching. Her conceptualization of teacher emotions can be taken as the starting point for the current study. She identified seven professional emotions that are frequently experienced when teaching, including enjoyment, pride, anger, anxiety, boredom, shame and pity. She determined the reasons behind the teachers' emotions, for example student achievement and success make teachers feel proud and happy. Teacher-student relationships evoke emotions in teachers, as a result of personal involvement with students. Another reason teachers experience emotions is student misbehaviour, which arouses negative emotions in teachers, for example anger and anxiety. Recently, a study by Burić, Slišković and Penezić (2019) showed that teachers' emotions and classroom practice are related to each other over time. For instance, feelings of love and care positively predicted classroom practice in which deep emotions were regulated, and feelings of anger positively predicted hiding feelings and faking emotions over time. The results of their study indicate the fostering of teachers' emotional well-being. In addition, Burić, Penezić and Sorić (2017) demonstrated that teachers are able to regulate their emotions and identified five distinct emotion-regulation strategies, namely, avoiding situations, active modification strategy, reappraisal, suppression and tension reduction. Teachers regulate their emotions by genuinely expressing their feelings when teaching, as well as performing surface acting and deep acting (Burić et al., 2019; Yin, 2016). These emotion regulation strategies help teachers fulfil their professional goals, and may therefore influence their well-being.

\section{Teaching disengaged students}

In classroom practice teachers have to deal with a group of students, who have different behaviours. The group may include students who exhibit disengaged behaviour such as resistance or opposition or they may be passive and lack motivation, all of which elicit negative emotions in teachers (Frenzel, 2014; Sanders, Munford \& Liebenberg, 2016; Spilt et al., 2011). Groenenberg and Hermannussen (2012a, 2012b) asked 255 Dutch teachers about their motivation levels for working with students at secondary vocational education where, according to Van der Steeg and Webbink (2006), there are high numbers of disengaged students and drop-outs in the Netherlands. The teachers in their study understood their teaching role in pedagogic terms and considered teaching to be an interesting challenge. They developed an interest in the students' behaviour and felt satisfaction when students performed well and were successful. Teachers also experienced positive emotions such as warmth, trust and pride from personal engage- 
ment with the students (Groenenberg \& Hermanussen, 2012a, 2012b). The teachers also pointed out that building up positive relationships with students takes a lot of time and energy. One teacher said: "it takes a terrifying amount of patience" and "you feel used" (Groenenberg \& Hermanussen, 2012 b, p. 41). Based on these reports, we assume that teaching disengaged students is accompanied by intense emotions. However, the amount of emotional load an individual teacher experiences will depends on the teacher's characteristics. Chang (2013) postulates that when teachers' correctly appraise students' behaviour they experience fewer negative emotions, and Maag (2008) reports that "when teachers avoid irrational thinking about a student's behaviour, their level of emotional upset automatically decreases, giving them the emotional control to figure out an effective response" (p. 56). This indicates that the emotions teachers experience depends on the context and the teachers' interpretation of the situation as well as their coping and emotion regulation strategies (Frenzel, 2014; Lazarus, 2006).

\section{Teachers' emotions and self-determination}

In the present study teachers' emotions were investigated using the affective motivational construct of Self-Determination Theory (SDT), which was originally developed to study human motivation and personality (Deci $\&$ Ryan, 1985). In the past 20 years the SDT has been used as a theoretical framework for investigating different issues including perceived well-being, which is also referred to as happiness (Ryan, Huta \& Deci, 2008; Ryan \& Deci, 2001, 2000). The concept of teachers' well-being or happiness that the SDT uses represents "intrinsically preferred states" (Ryan et al., 2008, p. 141), which can easily be identified by emotions such as interest or joy. These emotions are connected to another type of well-being, self-realization, which represents the perception of living a meaningful life (Ryan \& Deci, 2001). Emotions that are found in conjunction with self-realization (Ryan et al., 2008) can be considered the result of self-determined and authentic choices based on values and interests.

According to the SDT, the perceived well-being and quality of a teacher's performance is supported by the teacher's feelings of autonomy, competence and relatedness (Ryan \& Deci, 2001). People feel autonomous when they are respected and free to make their own choices. Feelings of competence are related to experiences of success and achievement. Relatedness is the desire to have caring relationships with others.

The feelings of autonomy, competence and relatedness are considered to 
be universal to all people (Church et al., 2012). However, these feelings can only be experienced in the context in which they emerge (De Stercke et al., 2015; Tadiç, Bakker \& Oerlemans, 2013). How teachers perceive autonomy, competence and relatedness in the classroom will depend on their characteristics (Howell, Chenot, Hill \& Howell, 2011) and so teachers report different perceptions in identical contexts.

\section{Teachers' feelings of autonomy, competence and relatedness}

Research about autonomy, competence and relatedness in education is usually focused on students' motivational behaviour (Haerens, Aelterman, Vansteenkiste, Soenens \& Van Petegem, 2015; Stroet, Opdenakker \& Minnaert, 2015; Van den Berghe, Cardon, Tallir, Kirk \& Haerens, 2016). However, some studies explore teachers' perceptions. According to Canrinus, Helms-Lorenz, Beijaard, Buitink and Hofman (2012) teachers' autonomy refers to when teachers feel free in their interactions with students and have the opportunity to adapt their teaching to the student. In addition, teachers' feelings of autonomy are also affected by the education system and the national achievement standards (Canrinus et al., 2012; Hargreaves, 2000, Moekotte, Brand-Gruwel \& Ritzen, 2017).

Feelings of competence refer to the desire to contribute effectively to established goals (Canrinus et al., 2012). For teachers, their work goals are related to their professional development, but can also focus upon students' learning goals. Experienced competence has a positive impact on teachers' perceived well-being and job satisfaction (Frederici \& Skaalvik, 2012; Klassen \& Ming Ming, 2010). However, developing competence requires persistence and effort. Therefore achieving competence can be considered to "ultimately maximize well-being" for teachers as defined by Howell et al. (2011, p. 13).

Spilt et al. (2011) suggest that the feeling of relatedness is primarily one in which teachers connect with their colleagues, just like other employees. In addition teachers also have the opportunity in their work to form a classroom relationship with the students (Klassen, Perry \& Frenzel, 2012). The intensity of this relationship will depend on the time they spend together and how mutual the relationship is between teacher and student (Hagenauer et al., 2015). Positive classroom relationships can be a source of joy, excitement, happiness and affection for both the teacher and the student (Hargreaves, 2000; Vallée \& Ruglis, 2017). According to Hargreaves (2000), teachers report high levels of stress when they feel neglected or a stranger 
to their students, suggesting that positive relationships are characterized by acknowledgement and respect. Teachers may experience intense emotions in their connections with students (Hargreaves, 2000). From the students' perspective, teachers should be a source of information and knowledge, reflecting the academic relationship between student and teacher (Sanders et al., 2016). However, students also seek recognition and wish to connect and feel safe in their relationship with the teacher before they can focus on their studies (Sanders et al., 2016). This indicates the student-teacher relationship is underpinned by emotional involvement and mutual engagement.

This study focusses on teachers who work with disengaged students and explores the emotions they experience in the classroom. We are interested in classroom practices with disengaged students because we presume - based on the literature - that these teachers experience intense emotions in relation to the typically negative classroom behaviours of disengaged students and their negative attitudes to school shaped by earlier experiences. The current study was conducted in a Secondary Vocational Education (SVE) school in the Netherlands where students are often disengaged through a lack motivation. The study explored two questions, namely teachers' emotions and how these emotions were connected to classroom practice. In addition teachers' emotions will be analysed in relation to the concept of wellbeing using the SDT, which proposes that feelings of autonomy, competence and relatedness foster higher levels of perceived well-being (see Figure 1). We asked the following research questions.

1. What elicits teachers' experienced emotions in their work with disengaged students in Secondary Vocational Education?

2. How do teachers' emotions relate to perceived well-being as defined by the feelings of autonomy, competence and relatedness?

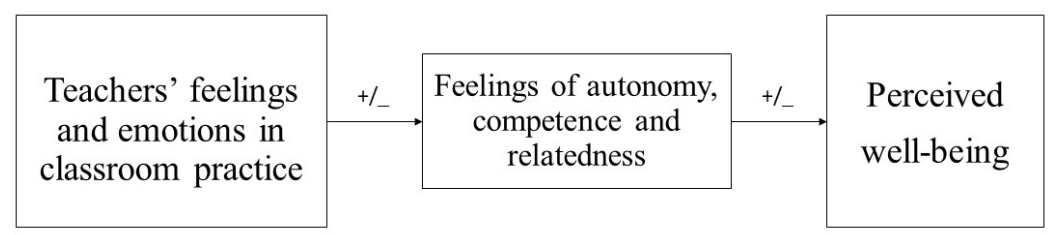

Figure 1 Conceptual model of the study: Teachers' feelings and emotions either prompt or prevent teachers' feelings of autonomy, competence and relatedness and affect teachers' perceived well-being 


\section{Methods}

A qualitative research approach was used in this study. In order to answer the research questions data were collected using focus group interviews with teachers. The teachers were interviewed about different issues, including their own emotions and feelings, when teaching disengaged students. We are aware of the limits of using group interviews especially when asking about teachers' personal feelings. Teachers may participate to different extents and one teacher may dominate over the others. However, the teachers had limited time to participate in the research so we decided to include emotions among the other interview questions relating to the curriculum and pedagogical approaches, which teachers were asked to evaluate every ten weeks together. To provide teachers with a safe environment in which to talk about their emotions and feelings, we decided to organize the groups so that each group was formed of teachers who knew each other very well and were used to discussing different issues together, including their feelings and emotions.

The aim of the interviews was to identify the teachers' emotions and to determine why they felt these emotions and to think about the situation in which the emotions occurred. The emphasis was on exploring teachers' practice and teachers were first asked to think about their work in general. For example, they were asked 'Are you satisfied?' and 'How do you feel about this group of students?'. After that, they were asked to elaborate on their answers and describe the situation in detail. For the in-depth data collection the teachers were followed for 18 months and interviewed every ten weeks, meaning that the same group of teachers was interviewed more than once by the same researcher. One advantage of organizing the interviews this way was that it gave the teachers greater opportunity to share their experiences (more moments), and these can change over the school year. In addition the researcher became acquainted with the teachers and the setting and could involve all the teachers more directly and ask more in-depth questions. Each interview took about an hour. During the interview briefing, teachers were informed about the aim of the interview questions and were asked if they would permit the information obtained to be used anonymously for the purposes of the research. A total of thirteen interviews were held. All the interviews were transcribed and anonymized. To improve the validity, member checks were done by presenting preliminary results to the teachers. They did not request any changes. 


\section{Participants}

The selection of the teachers was not random; the schools and teachers were selected because they were following a programme aimed at disengaged students (Fix, 2018; Fix, Ritzen, Pieters \& Kuiper, 2019). The interview groups were formed of teachers who worked together at the same school. There were three groups of four teachers and in one school a group of two teachers. The participating teachers $(\mathrm{N}=14)$ were qualified and had a teaching licence. They had different specialisms and experience (see Table 1).

Table 1 Overview of participants' characteristics

\begin{tabular}{|c|c|c|c|c|c|}
\hline & ID & Gender & Age (years) & Experience (years) & Work experience \\
\hline \multirow{4}{*}{ School A } & A & Female & $>50$ & $>15$ & VET \\
\hline & $\mathrm{B}$ & Male & $30-40$ & $5-15$ & Social work \\
\hline & $\mathrm{C}$ & Male & $20-30$ & $<5$ & Social work \\
\hline & $\mathrm{D}$ & Male & $30-40$ & $5-15$ & Social work \\
\hline \multirow{4}{*}{ School B } & $\mathrm{E}$ & Female & $30-40$ & $<5$ & VET \\
\hline & $\mathrm{F}$ & Female & $20-30$ & $<5$ & Social work \\
\hline & $\mathrm{G}$ & Male & $20-30$ & $<5$ & Job coach \\
\hline & $\mathrm{H}$ & Female & $40-50$ & $5-15$ & SVE \\
\hline \multirow{2}{*}{ School C } & I & Male & $>50$ & $>15$ & VET \\
\hline & $\mathrm{J}$ & Male & $30-40$ & $5-15$ & SVE \\
\hline \multirow{4}{*}{ School D } & $\mathrm{K}$ & Male & $40-50$ & $>15$ & SVE \\
\hline & $\mathrm{L}$ & Female & $30-40$ & $>15$ & SVE \\
\hline & M & Female & $30-40$ & $>15$ & SVE \\
\hline & $\mathrm{N}$ & Female & $30-40$ & $5-15$ & SVE \\
\hline
\end{tabular}

*Note: SE = Special education, SVE = Secondary Vocational Education Institute

\section{Data analysis}

After collecting the interview data, the researchers followed a series of steps to analyse the data. To organize and analyse the data we used a software program (ATLAS.ti). 


\section{Step 1}

To answer research question one, all the interviews were read and the statements where teachers referred to positive feelings or emotions were highlighted. An inductive approach was used to select the statements.

\section{Step 2}

Next the positive statements $(\mathrm{n}=76)$ were summarized so as to present the key message of the passage. The summaries were included in the database and labelled as positive statements.

\section{Step 3}

Subsequently the interviews were read again and the statements where teachers referred to negative feelings or emotions were highlighted. An inductive approach was used to select the statements.

\section{Step 4}

Next the negative statements $(n=32)$ were summarized so as to present the key message of the passage. The summaries were included in the database and labelled as negative statements.

\section{Step 5}

For every summarized passage, first the experienced emotion was identified, yielding a list of different identified emotions (Table 2), and second the emotions were clustered into themes, resulting in the main themes relating to the emotions. Next the reasons for the emotions were identified, yielding a list of reasons. The reasons were then clustered into four main causes (Table 3).

\section{Step 6}

To answer the second research question, we performed an in-depth analysis of the identified reasons for the emotions and investigated how these reasons supported the teachers' feelings of autonomy, competence and relatedness.

To enhance reliability and validity, two researchers worked together to analyse the first three transcribed interviews (step 1-step 5). Subsequently the researchers analysed the other transcripts separately and discussed the analysis. They identified the emotions and their causes (step 1-step 4) and established general themes. These were discussed until a consensus was reached (step 5). After that the head researcher performed an in-depth analysis of the concepts of autonomy, competence and relatedness (step 6) 
and the findings were discussed with the second researcher. The transcriptions were then read again: no information was found that could falsify the findings.

\section{Results}

The first research question was aimed at identifying the reason for the teachers' emotions in the classroom. We have included quotes by the teachers to facilitate a better interpretation of the findings. The teachers' identifiers are presented (see Table 1) as well as the chronological number of the interview by school. We first focus on the statements that represent teachers' positive emotions.

\section{Positive emotions}

The first reason given for positive classroom emotions relates to contact and personal relationships with students. Aspects such as 'talking to students', 'getting to know them' and 'have a good time together' evoked positive feelings for teachers: "I really like having fun with the students and making it pleasant for all of us" (teacher B, school A, interview 2). Furthermore, teachers experienced positive emotions when students showed respect, supported and encouraged them: "I had a difficult period in my private life, but the support of the students gave me the energy to be here every morning" (teacher $\mathrm{C}$, school A, interview 5). In addition, caring relationships and positive interactions between students were also sources of positive emotions and teachers were surprised at how supportive peers can be of one another: "The students understand each other, that felt very special for me" (teacher B, school A, interview 2). Teachers also enjoyed it when students were presented positively in front of others, such as parents, which made the teachers proud: "What I liked very much was that we could tell his parents that we were very proud of him" (teacher L, school D, interview 5).

A second reason for positive feelings was related to student progress. Teachers mentioned feeling pride and joy when students made progress: "A lot of things happened in this group of students, that were fantastic and special for me, these students have made big steps" (teacher A, school A, interview 3).

Students' behaviour was another source of teachers' positive emotions. Unsurprisingly, student engagement evoked positive feelings and teachers enjoyed working with active, interested students. However, according to teachers, student engagement was often preceded by inappropriate class- 
room behaviour. This behaviour elicited interest in teachers, who were curious as to why the students behaved in such a way: "I say to students (... ) you make me curious what's behind your behaviour and then I start asking questions(...) a lot of questions (laughs)" (teacher A, school A, interview 5). Teachers reported liking it when students were genuine and expressed their emotions, "For me it was a very special group of students, they were all very open" (teacher A, school A, interview 4), even if it triggered aggressive or depressive emotions. In general the teachers were interested in the students' behaviour, especially challenging, emotional behaviour that the student's had difficulty controlling. Teachers had positive feelings when students transitioned from inappropriate behaviour to interested and engaged behaviour: "After that, the student decided to participate in the learning activity, he wanted to hear his strengths, I felt that was a great moment" (teacher $\mathrm{H}$, school B, interview 3).

Other sources of positive emotions were associated with colleagues. Firstly teachers felt happy when they worked together as a team with their colleagues: "It works very well when we bring different competencies (....), that is a big gain" (teacher K, school D, interview 2). Secondly teachers experienced positive emotions when they felt appreciated and that their work was respected by colleagues: "It felt good when one of my colleagues said that he valued the programme" (teacher $\mathrm{K}$, school D, interview 5).

Two other reasons teachers had positive feelings referred to successful adaptation of the learning activities to students' needs and a sense of responsibility in teaching the programme and the students: "You are seen as the public face of the programme, that gives a lot of satisfaction" (teacher $\mathrm{K}$, school D, interview 2). Table 3 summarizes the findings on the reasons teachers had positive emotions.

\section{Negative emotions}

Most negative emotions were related to teaching practices in which teachers felt a strong personal involvement with their students, especially when searching for effective approaches to help and support the students. For example, the following was stated in relation to students sharing their problems: "It kept me awake at night thinking about how I could help them" (teacher A, school A, interview 2) and "(...) every time she is late I'm thinking is she still alive?(...) She doesn't want to live anymore, that is heavy for me" (teacher A, school A, interview 5). Teachers mentioned that they were sometimes motivated to go beyond their own limits: "I had to go beyond my own limits to help her" (teacher A, school A, interview 3) and "I had to do some- 
Table 2 Overview of teachers' emotions

\begin{tabular}{|l|l|l|}
\hline & Reported feelings & \\
\hline & Enjoyment & Challenge \\
& Pleasure & Responsibility \\
& Fun & Energy \\
& Enthusiasm & Interest \\
& Satisfaction & Warmth \\
& Pride & Support \\
& Appreciation & Connection \\
& Success & Vulnerability \\
& Achievement & Sensitiveness \\
\hline \multirow{5}{*}{ Negative emotions } & Stress & Loneliness \\
& Tension & Vulnerability \\
& Frustration & Anxiety \\
& Irritation & Failure \\
& Uncertainty/doubt & Dissatisfaction \\
\hline
\end{tabular}

thing to change the negative process, I was also very negative, I lost myself in it (...) I had to motivate myself again" (teacher A, school A, interview 2). Teachers also talked of inappropriate pedagogies that evoked negative emotions: "I didn't reach the students, that's frustrating" (teacher E, school B, interview 3) and "Sometimes I really wonder what the right question was to help, I had to do my very best" (teacher A, school A, interview 2).

Another reason teachers experienced negative emotions was their colleagues. Teachers talked of a lack of shared responsibility, peer feedback and a failure to stick to agreements. They also mentioned differences in pedagogical strategies and vision: "We have to get them to face up more to the life they are living (...) but I feel like I'm the only one who thinks that is the right thing to do" (teacher I, school C, interview 4).

Furthermore, student progress evoked negative feelings in teachers, primarily regarding student learning outcomes and their contribution to student learning: "I don't feel satisfied (.....) there are two or three students that have made too little progress (...) I think, what a pity, what can we do better" (teacher E, school B, interview 2).

Negative feelings were also caused by organizational aspects of the teaching programme. Teachers felt that the way the school day was organized sometimes made it difficult for them to give good guidance to the students: "I don't have time to talk to the students, (...) in my break I have to get my classroom ready, so the opportunity to talk is lost" (teacher E, school B, interview 3). 
Table 3 Overview of reasons for emotions

\begin{tabular}{|c|c|c|}
\hline Emotions & \multicolumn{2}{|l|}{ Reasons for emotions } \\
\hline Students & $\begin{array}{l}\text { Positive emotions } \\
\text { Sharing personal stories } \\
\text { Talking to students and getting to } \\
\text { know them } \\
\text { Peer interaction } \\
\text { Positive performance by students } \\
\text { Emotions expressed by students } \\
\text { Students' classroom behaviour }\end{array}$ & $\begin{array}{l}\text { Negative emotions } \\
\text { Becoming too emotionally involved } \\
\text { Pedagogical issues }\end{array}$ \\
\hline Colleagues & $\begin{array}{l}\text { Positive emotions } \\
\text { Teamwork } \\
\text { Appreciation of their work }\end{array}$ & $\begin{array}{l}\text { Negative emotions } \\
\text { Lack of feedback and help from } \\
\text { colleagues } \\
\text { No shared responsibilities } \\
\text { Different opinions about pedago- } \\
\text { gies }\end{array}$ \\
\hline Students' learning & $\begin{array}{l}\text { Positive emotions } \\
\text { Student progress } \\
\text { Personal contribution to students' } \\
\text { learning }\end{array}$ & $\begin{array}{l}\text { Negative emotions } \\
\text { Personal contribution to progress } \\
\text { Learning outcome } \\
\text { Pedagogical issues } \\
\text { Lack of personal competencies }\end{array}$ \\
\hline $\begin{array}{l}\text { Programme and } \\
\text { organization }\end{array}$ & $\begin{array}{l}\text { Positive emotions } \\
\text { Potential to adapt programmes to } \\
\text { students } \\
\text { Programme }\end{array}$ & $\begin{array}{l}\text { Negative emotions } \\
\text { Dissatisfaction about programm } \\
\text { Inability to give appropriate guid- } \\
\text { ance to students }\end{array}$ \\
\hline
\end{tabular}

\section{Perceptions of autonomy, competence and relatedness}

Research question two was focused upon teachers' emotions relating to autonomy, competence and relatedness.

Regarding relatedness, teachers experienced positive emotions including the joy and pleasure of classroom interaction and contact with students, which was reported as talking to each other, having fun and spending time together. Teachers also reported more intense emotions arising out of contact with students such as appreciation, respect, warmth and support. These emotions occurred primarily when they engaged in activities that enabled students and teachers to share personal stories with each other and be open about feelings and express high levels of mutual involvement. In addition, as mentioned before, teachers referred to negative emotions they experienced when becoming intensely and personally involved. These were primarily feelings of doubt and uncertainty about the teacher's strategy and pedagogies to support students but also being worried about students' problems. 
Besides their relationships with the students, teachers also felt connected to their colleagues and felt trust and support because they worked as a team and felt appreciated by their colleagues. Regarding their colleagues, teachers' reported negative emotions in relation to teamwork or team spirit. These related to, for example, a lack of shared responsibility for the programme, lack of colleague feedback, and lack of shared pedagogical approaches to support students.

In relation to competence, teachers primarily considered competence in relation to students' success, as they reflected upon their own role in student learning and behaviour: "For example a girl that had made good progress and visited me personally to tell what I meant to her, that is really great" (teacher B, school A, interview 3). Teachers attributed learning outcomes or positive changes in students' behaviour to their own role, which made them feel proud, satisfied and happy but also evoked feelings of doubt and uncertainty about their own competence when they felt that students' learning was not optimally supported or that students' were not making progress.

Autonomy was expressed as the freedom to adapt the programme and identify ways of coaching and guiding the students. These evoked feelings of responsibility, pride and satisfaction. However, teachers sometimes lacked opportunities to guide students in an optimal way because of financial issues or organizational limits, and this limited their experienced autonomy and evoked feelings of frustration and dissatisfaction.

\section{Conclusion}

The aim of this study was to investigate teachers' emotions in the classroom and how emotions related to their perceived well-being. Based on our literature study we hypothesized that teachers' perceived well-being was affected by emotions experienced during classroom practice through perceptions of autonomy, competence and relatedness (see our conceptual model, Figure 1). In our results we reported that teachers experienced mixed emotions elicited by their interactions with students, student learning, colleagues and the programme (see also Table 3). Figure 2 conceptually structures our findings showing how emotions were evoked (research question 1) and how these emotions were related to autonomy, competence and relatedness (research question 2). 


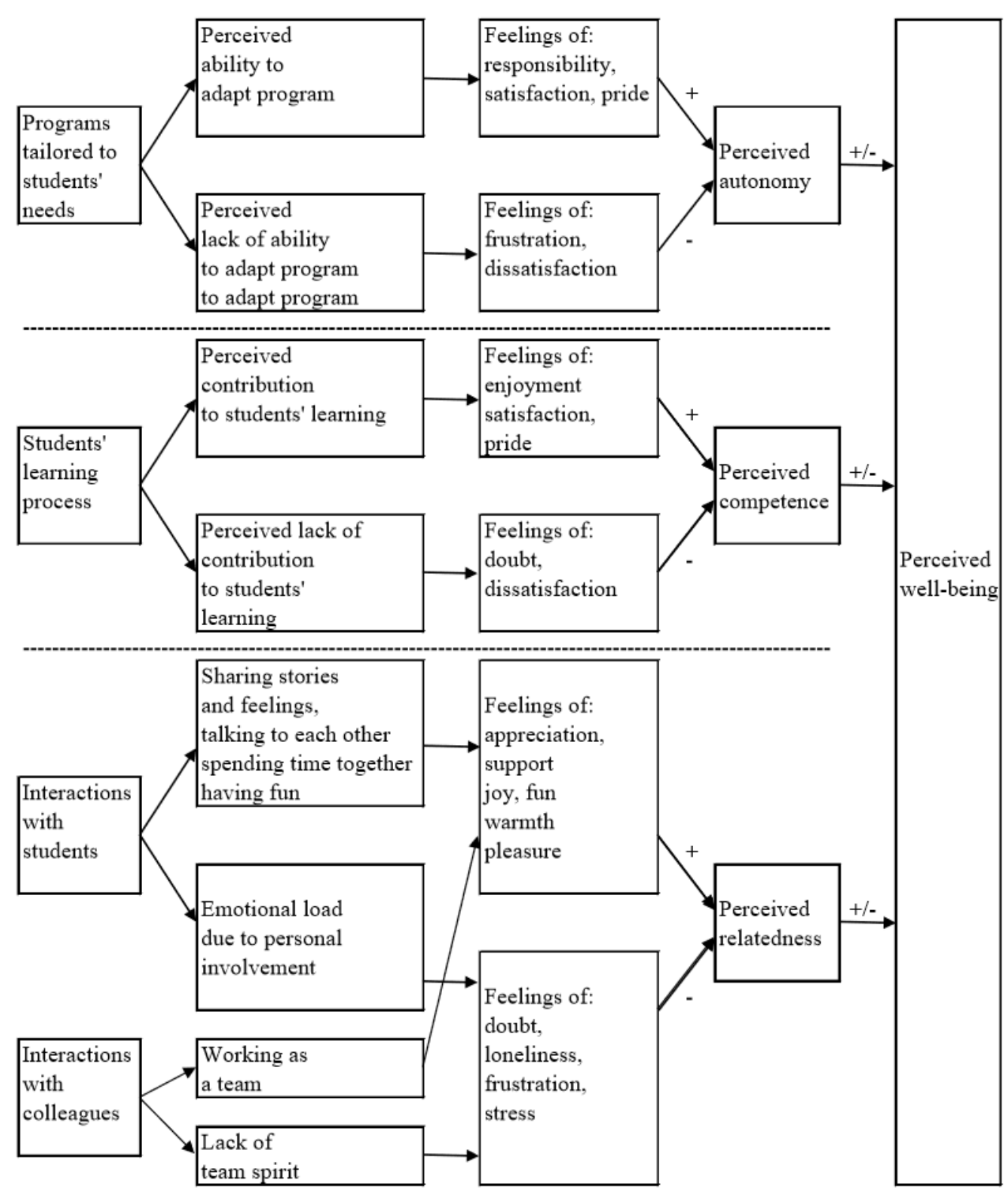

Figure 2. Conceptualization of the findings: what elicits emotions that support or diminish teachers' feelings of autonomy, competence and relatedness and their perceived well-being

\section{Discussion}

In the present study we researched teachers' emotions relating to classroom practice and how emotions expressed individual perceptions of autonomy, competence and relatedness, which are considered supportive for perceived well-being as conceptualized by SDT (Ryan et al., 2008). 
The findings of our study show the implicit complexity of classroom emotions. For example, working in a team can be a source of positive emotions for teachers as they feel the responsibility is shared. Working in a team, however, does not guarantee positive emotions, as teachers also reported feeling frustrated and lonely because of the lack of shared goals and differences in pedagogical approaches. These findings imply that the way a team operates in practice is important. Another point of interest is that teachers sometimes reported negative emotions but implicitly also mentioned that this prompted them to improve classroom practices, which may have a positive impact. For example, a teacher who was dissatisfied with student progress asked herself what she could do to improve it. The qualitative approach adopted in our study did not investigate the reciprocal effects of classroom emotions; however, we think this information will contribute to the knowledge on classroom emotions in relation to teacher well-being.

Furthermore, the findings provided some interesting insights into teachers' perceptions of inappropriate student behaviour in the classroom. We expected this behaviour would elicit negative emotions, based on earlier research (Frenzel, 2014; Spilt et al., 2011). However, teachers did not report experiencing negative emotions in relation to students' classroom behaviour, although we noticed during the data collection that misbehaviour was often in evidence in the classroom. We assume that teachers regulated classroom emotions in an effective pedagogical way that reduced stress for them. In the next section we will elaborate on that.

Based on the present study and supported by Aldrup, Klusmann, Lüdtke, Göllner and Trautwein (2018) and Jennings and Greenberg (2009), we argue that teacher-student interaction was used as a means of reducing student misbehaviour in the classroom and, subsequently, of enhancing the level of positive classroom emotions. To better understand how teachers used teacher-student interaction to create a more positive classroom atmosphere, we need to explain the context within which the teachers were working.

The participating teachers in our study all taught a special programme aimed at disengaged students and had the opportunity to build up strong relationships with students owing to intensive contact with the students, a high teacher-student ratio and student-centred pedagogies that included coaching students within the framework of their individual learning goals. According to the literature these characteristics are all considered beneficial for teacher-student relationships (Bosworth, 2014; Gándara, Larson, Mehan \& Rumberger, 1998; Sanders et al., 2016). We argue that this context 
made teachers more alert to the smallest (negative) changes in the students' emotions and behaviour. Moreover teachers intervened whenever they noticed students behaving negatively or exhibiting negative emotions. They took time to talk to the students so as to gain some understanding of why the students were engaging in inappropriate classroom behaviours or emotions. They could then respond in an effective and personal manner, which strengthened the teacher-student relationship and reduced stress levels in the classroom, both for students as well as teachers.

Furthermore, teachers were well-prepared to handle emotions in the classroom as they rarely deliberately provoked students' emotions. The teachers wanted to teach students how to regulate these feelings in an appropriate manner in classroom settings. We suggest that by doing that teachers contributed to a positive classroom climate because they allowed the students to express and discuss their emotions and feelings. In addition the teachers prepared coping strategies to handle students' emotions and shared their own feelings with students. This proactive approach to handling students' emotions reduced the teachers' stress, as they were not taken by surprise when emotions were elicited and took time to talk about them and share them with students and this reduced the stress in the classroom. This finding is in line with the work of Yin, Huang and Lv (2018) who reported a relation between emotional appraisal strategies and teachers' well-being. As noted before, the emotional involvement between teacher and students elicits intense emotions in teachers, such as pride and satisfaction, but also frustration, disappointment and doubt, and these even kept teachers awake at night. The work of Taxer and Frenzel (2015) shows that teachers in classroom settings have a tendency to supress their negative emotions and fake positive emotions, which indicates that teachers engage in emotional inauthenticity' in the classroom and this may lead to more intense negative emotions in teachers (Burić et al., 2019). Based on our finding regarding the coping strategies the teachers in our study used to handle emotions, we suppose that expressing negative emotions enhances teachers' well-being, which was also reported by Taxer and Frenzel (2015). In addition, we argue that in our study expressing emotions, including negative feelings, may strengthen the relationship with students, as 'authentic acting' between students and teachers was seen as essential to positive student development.

Although this study has yielded some interesting information, we have to make some criticisms. First, the selection of the teachers could have influenced our findings. The teachers were selected by their schools and taught on programmes aimed at disengaged students. This decision was deliberate 
as we wished to focus explicitly on feelings and emotions. Secondly, the presented results are based on data collected through focus group interviews. We chose group interviews instead of individual interviews for practical reasons. Nonetheless, we are aware that this type of social interaction may lead to biased findings (Kitzinger, 1994).

Finally we want to emphasize that this research was conducted within a relativistic paradigm. The insights and information must therefore be interpreted within the context in which they were obtained and should only be transferred with caution.

This study focused on teachers' classroom emotions. To expand the knowledge on classroom emotions it might be useful to include students' emotions in future research because teachers' emotions are influenced by students and vice versa.

Furthermore for more robust results we suggest expanding the knowledge directly acquired from the programmes-in-action. For example, this could involve observations, which would provide insights on actual classrooms situations in addition to teachers' perceptions.

\section{Implications for practice}

Based on the conceptualization in Figure 2 we conclude that the following characteristics of classroom practices that contribute to teachers' perceived well-being:

- Practices in which teachers feel free to adapt and evolve the programme to reflect students' needs.

- Practices in which teachers have the opportunity to support students' individual learning and to determine their personal contribution to students' success and achievement.

- Practices that allow teachers to interact with students as part of normal classroom contact, such as talks and chats. And that allow teachers to have more emotional contact through sharing personal stories and feelings with students.

- Practices in which teachers have the opportunity work closely together with colleagues, expressed by a shared programme vision, goals and responsibilities.

In addition we postulate that the following classroom characteristics diminish teachers' perceived well-being. 
- Practices in which teachers are prevented from adapting the programme in the best way possible to reflect students' needs, for organizational or financial reasons.

- Practices in which teachers do not feel able to support students in an optimal way, for example because they experience a lack of pedagogical skills or competences.

- Practices in which teachers feel their personal involvement with the students creates an excessive emotional load, for example when they feel pushed into going beyond their own limits or worry too much about individual students.

- Practices in which teachers work alone or lack support from colleagues

Lastly, we presume that not every teacher will experience positive feelings when working with disengaged students. Based on the present study and its conceptual background, we argue that classroom contexts in general, but especially contexts tailored to disengaged students, require teachers who:

- Have a special interest in this category of student, primarily because of their behaviour

- Are excellent pedagogues, who are aware of the needs of disengaged students

- Are open about their personal emotions and are brave enough to withstand feeling vulnerable

- Reflect critically on their own practices and moreover upon their own role, competences and short-comings

- Are open to colleague feedback and discussions

- Are capable of defining and defending their own limits

- Take responsibility for their students and the programme

\section{Declaration statement and acknowledgements}

The content of this submission has not been published or submitted for publication elsewhere and the authors have no competing interests or issues relating to the journal policies. All the participants in this study participated on a voluntary basis and gave permission for their anonymous data to be published. Funding and acknowledgements are not applicable.

\section{References}

Aldrup, K., Klusmann, U., Lüdtke, O., Göllner, R., \& Trautwein, U. (2018). Student misbehavior and teacher well-being: Testing the mediating role of the teacher-student relationship. Learning and Instruction, 58, 126-136. 
Bosworth, R. (2014). Class size, class composition, and the distribution of student achievement. Education Economics, 22(2), 141-165.

Bullough Jr, R. V., \& Pinnegar, S. (2009). The happiness of teaching (as eudaimonia): Disciplinary knowledge and the threat of performativity. Teachers and Teaching: Theory and Practice, 15(2), 241-256.

Burić, I., Penezić, Z., \& Sorić, I. (2017). Regulating emotions in the teacher's workplace: Development and initial validation of the teacher emotion-regulation scale. International Journal of Stress Management, 24(3), 217-246.

Burić, I., Slisković, A., \& Penezić, Z. (2019). A two-wave panel study on teachers' emotions and emotional-labour strategies. Stress \& Health, 35(1), 27-38.

Canrinus, E. T., Helms-Lorenz, M., Beijaard, D., Buitink, J., \& Hofman, W. H. A. (2012). Self-efficacy, job satisfaction, motivation and commitment: Exploring the relationship between indicators of teachers' professional identity. European Journal of Psychology of Education, 27(1), 115-132.

Chang, M-L. (2013). Toward a theoretical model to understand teacher emotions and teacher burnout in the context of student misbehavior: Appraisal, regulation and coping. Motivation \& Emotions, 37, 799-817.

Chang, M-L. (2009). An appraisal perspective of teacher burnout: Examining the emotional work of teachers. Educational Psychology Review, 21, 193-218.

Church, A. T., Katigbak, M. S., Locke, K. D., Zhang, H., Shen, J., Vargas-Flores, J. J.,...\& Ching, C. M. (2012). Need satisfaction and well-being: Testing self-determination theory in eight cultures. Journal of Cross-Cultural Psychology, 44(4), 507-534. Deci, E., \& Ryan, R. M. (1985). Intrinsic motivation and self-determination in human behavior. New York: Springer Science \& Business Media.

Deci, E. L., \& Ryan, R. M. (2000). The 'what' and 'why' of goal pursuits. Human needs and the self-determination of behaviour. Psychology Inquiry, 11, 227-268.

De Stercke, J., Goyette, N., \& Robertson, J. E. (2015). Happiness in the classroom: strategies for teacher retention and development. Prospects, 45(4), 421-427.

Federici, R. A., \& Skaalvik, E. M. (2012). Principal self-efficacy: Relations with burnout, job satisfaction and motivation to quit. Social Psychology of Education, 15(3), 295-320.

Fix, G. M. (2018). The football stadium as classroom: Exploring a program for at-risk students in secondary vocational education. (doctoral dissertation). University of Twente: Enschede.

Fix, G. M., Ritzen, H. T. M., Pieters, J. M., \& Kuiper, W. A. J. M. (2019). Effective curricula for at-risk students in vocational education: a study of teachers' practice. Empirical research in vocational education and training, 11(1), 1.

Fredricks, J. A., Blumenfeld, P. C., \& Paris, A. H. (2004). School engagement: Potential of the concept, state of the evidence. Review of Educational Research, 74, 59-109. Frenzel, A. C. (2014). Teacher emotions. In E. A. Linnenbrink-Garcia, \& R. Pekrun (Eds.), International Handbook of Emotions in Education (pp. 494-519). New York: Routledge.

Frenzel, A. C., Goetz, T., Lüdtke, O., Pekrun, R., \& Sutton, R. E. (2009). Emotional transmission in the classroom: Exploring the relationship between teacher and student enjoyment. Journal of Educational Psychology, 101(3), 705-716.

Gándara, P., Larson, K., Mehan, H., \& Rumberger, R. (1998). Capturing Latino stu- 
dents in the academic pipeline. UC Berkeley: Center for Latino Policy Research. Retrieved from https://escholarship.org/uc/item/84h2j4qs.

Groenenberg, R., \& Hermanussen, J. (2012a). Met inzet, geduld en maatwerk: Lesgeven aan deelnemers in mbo niveau 1 en 2. [With effort, patience and matching: Teaching students at secondary vocational education level 1 and 2]. Report. Expertisecentrum Beroepsonderwijs. [Expert center vocational education]. Utrecht.

Groenenberg, R., \& Hermanussen, J. (2012b). Docent in mbo niveau 1 en 2: Een vak apart [ Teaching level 1 and 2 in secondary vocational education: A special job]. Report. Expertisecentrum Beroepsonderwijs. [Expert centre of vocational education]. Utrecht.

Haerens, L., Aelterman, N., Vansteenkiste, M., Soenens, B., \& Van Petegem, S. (2015). Do perceived autonomy-supportive and controlling teaching relate to physical education students' motivational experiences through unique pathways? Distinguishing between the bright and dark side of motivation. Psychology of Sport and Exercise, 16, 26-36.

Hagenauer, G., Hascher, T., \& Volet, S. E. (2015). Teacher emotions in the classroom: Associations with students' engagement, classroom discipline and the interpersonal teacher-student relationship. European Journal of Psychology of Education, 30(4), 385-403.

Hargreaves, A. (2000). Mixed emotions: Teachers' perceptions of their interactions with students. Teaching and Teacher Education, 16, 811-826.

Howell, R. T., Chenot, D., Hill, G., \& Howell, C. J. (2011). Momentary happiness: The role of psychological need satisfaction. Journal of Happiness Studies. 12, 1-15.

Jalali, Z., \& Heidari, A. (2016). The relationship between happiness, subjective well-being, creativity and job performance of primary school teachers in Ramhormoz city. International Educational Studies, 9(6), 45-52.

Jennings, P. A., \& Greenberg, M. T. (2009). The prosocial classroom: Teacher social and emotional competence in relation to student and classroom outcomes. Review of Educational Research, 79(1), 491-525.

Klassen, R., \& Ming Ming, C. (2010). Effects on teachers' self-efficacy and job satisfaction: Teacher gender, years of experience, and job stress. Journal of Educational Psychology, 102(3), 741-756.

Klassen, R. M., Perry, N. E., \& Frenzel, A. C. (2012). Teachers' relatedness with students: An underemphasized component of teachers' basic psychological needs. Journal of Educational Psychology, 104(1), 150-165.

Kitzinger, J. (1994). The methodology of focus groups: The importance of interaction between research participants. Sociology of health \& illness, 16(1), 103-121.

Lazarus, R. S. (2006). Emotions and interpersonal relationships: Toward a person-centred conceptualization of emotions and coping. Journal of Personality, 74(1), 9-46.

Maag, J. W. (2008). Relational-emotive therapy to help teachers control their emotions and behavior when dealing with disagreeable students. Intervention in School and Clinic, 44 (1), 52-57.

Maslach, C., Schaufeli, W. B., \& Leiter, M. P. (2001). Job burnout. Annual Review of Psychology, 52(1), 397.

Moekotte, P. B. F., Brand-Gruwel, S., \& Ritzen, H. T. M. (2017). Teachers` beliefs 
about using technology to enhance the learning process of at-risk-students. International Journal of Social Media and Interactive Learning Environments, (5)2, 108-136. Pekrun, R. (2017). Emotion and achievement during adolescents. Child Development Perspectives, 11(3), 215-223.

Ryan, R. M., \& Deci, E. L. (2001). On happiness and human potentials: A review of research on hedonic and eudaimonic well-being. Annual Review of Psychology, 52, 141-166.

Ryan, R. M., \& Deci, E. L. (2000). Self-determination theory and the facilitation of intrinsic motivation, social development, and well-being. American Psychologist, 55, 68-78.

Ryan, R. M., Huta, V., \& Deci., E. L. (2008). Living well: A self-determination theory perspective on eudaimonia. Journal of Happiness Studies, 9, 139-170.

Sanders, J., Munford, R., \& Liebenberg, L. (2016). The role of teachers in building resilience of at-risk youth. International Journal of Educational Research, 80, 111-123. Shen, B., McCaughtry, N., Martin, J., Garn, A., Kulik, N., \& Fahlman, M. (2015). The relationship between teacher burnout and student motivation. British Journal of Educational Psychology, 85(4), 519-532.

Spilt, J. L., Koomen, H. M. Y., \& Thijs, J. T. (2011). Teacher wellbeing: The importance of teacher-student relationships. Educational Psychology Review, 23, 457- 477.

Stroet K. F. A., Opdenakker M., \& Minnaert A. (2015). Need supportive teaching in practice: a narrative analysis in schools with contrasting educational approaches. Social Psychology of Education, 18(3), 585-613.

Tadiç, M., Bakker, A. B., \& Oerlemans, W. G. M. (2013). Work happiness among teachers: A day reconstruction study on the role of self-concordance. Journal of School Psychology, 51, 735-750.

Taxer, J. L., \& Frenzel, A. C., (2015). Facets of teachers' emotional lives: A qualitative investigation of teachers' genuine, faked and hidden emotions. Teaching and Teacher Education, 49, 78-88.

Vallée, D., \& Ruglis, J. (2017). Student disengagement in English-speaking Montréal. Educational Studies, 53(3), 285- 314.

Van den Berghe, L., Cardon, G., Tallir, I., Kirk, D., \& Haerens, L. (2016). Dynamics of need-supportive and need-thwarting teaching behavior: the bidirectional relationship with student engagement and disengagement in the beginning of a lesson. Physical Education and Sports Pedagogy, 21(6), 653-670.

Van der Steeg, M., \& Webbink, D. (2006). Voortijdig schoolverlaten in Nederland: omvang, beleid en resultaten (No. 107) [Early school leaving in the Netherlands: size, policy and results]. Centraal Planbureau.

Veldman, I., Tartwijk, van, J., Brekelmans, M., \& Wubbels, T. (2013). Job satisfaction and teacher-student relationship across teaching career: Four case studies. Teaching and Teacher Education, 32(1), 55-65.

Yin, H. (2016). Knife-like mouth and tofu-like heart: Emotion regulation by Chinese teachers in classroom teaching. Social Psychology of Education, 19(1), 1-22.

Yin, H., Huang, S., \& Lv, L. (2018). A multilevel analysis of job characteristics, emotions regulation and teacher well-being: A job demands-resources model. Frontiers in Psychology, 9, article ID 2395. 


\section{Authors}

G. M. Fix, Ph.D.

University of Groningen

Faculty of Behavioral and Social Science

Postbus 72

9700 AB Groningen

Netherlands

Email:mfix@landstede.nl

H. T. M. Ritzen, Ph.D.

Saxion University of Applied Science

M.H. Tromplaan 28

7513 AB Enschede

Netherlands

Email: hritzen@rocvantwente.nl

J. M. Pieters, prof.

University of Twente

Faculty of Behavioral, Management and Social Science

Drienerlolaan 5

7522 NB Enschede

Netherlands

Email: j.m.pieters@utwente.nl

W. A. J. M. Kuiper, prof.

Utrecht University

Faculty of Science

Heidelberglaan 8

3584 CS Utrecht

Netherlands

Email:W.Kuiper@uu.nl 